\title{
HUKUM WAKAF UANG DAN WAKAF PRODUKTIF
}

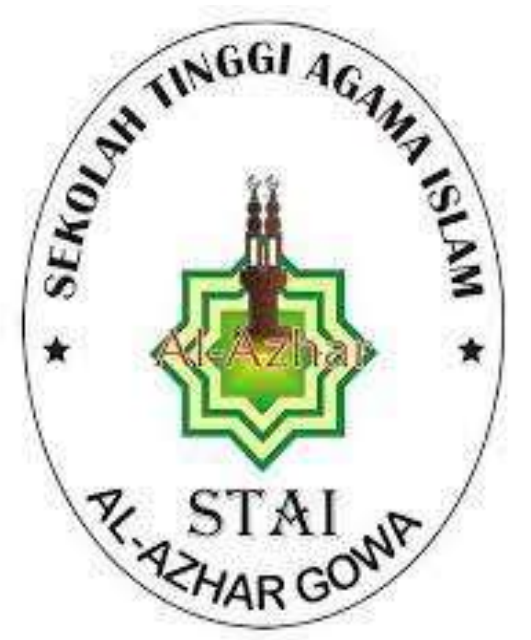

Makalah Diajukan untuk memenuhi tugas mata kuliah

fikih zakat dan wakaf

Oleh :

Masni

Nurhalisa Hasanuddin

Dosen :

Samsul Arifai, S.A.B., M.A.

\section{EKONOMI SYARIAH \\ STAI AL-AZHAR GOWA}

2021 


\section{KATA PENGANTAR}

Puji syukur diucapkan kehadirat Allah SWT atas segala rahmatNya sehingga makalah ini dapat tersusun sampai dengan selesai. Tidak lupa kami mengucapkan terimakasih terhadap bantuan dari pihak yang telah berkontribusi dengan memberikan sumbangan baik pikiran maupun materinya.

Penulis sangat berharap semoga makalah ini dapat menambah pengetahuan dan pengalaman bagi pembaca. Bahkan kami berharap lebih jauh lagi agar makalah ini bisa pembaca praktekkan dalam kehidupan sehari-hari.

Bagi kami sebagai penyusun merasa bahwa masih banyak kekurangan dalam penyusunan makalah ini karena keterbatasan pengetahuan dan pengalaman Kami. Untuk itu kami sangat mengharapkan kritik dan saran yang membangun dari pembaca demi kesempurnaan makalah ini.

Makassar, 22 Desember 2021

Penulis 


\section{DAFTAR ISI}

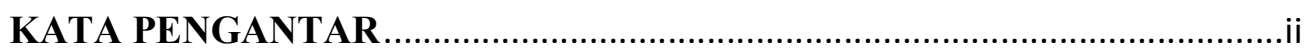

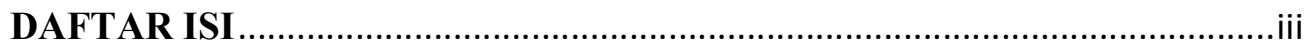

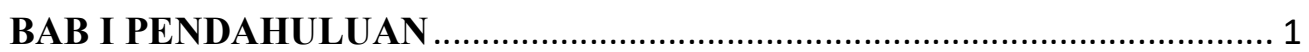

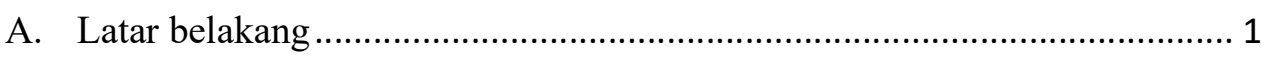

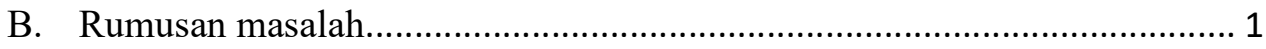

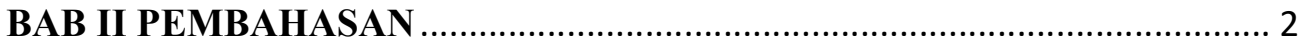

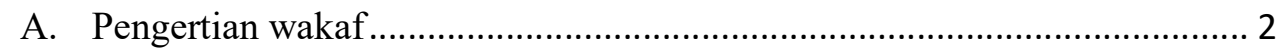

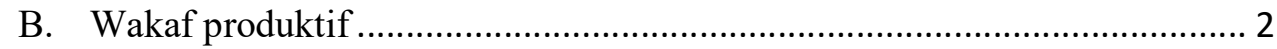

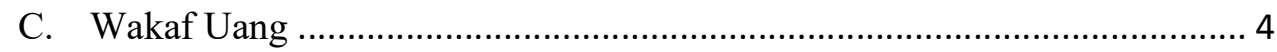

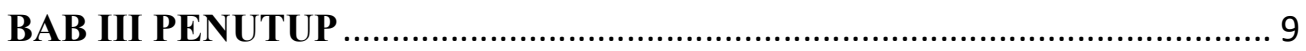

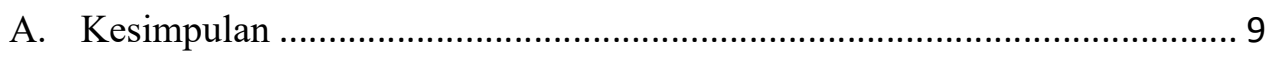

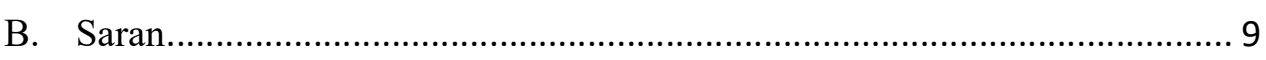

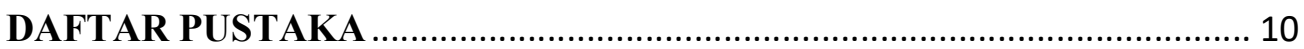




\section{BAB I}

\section{PENDAHULUAN}

A. Latar belakang

Sebagaimana dimaklumi bahwa di antara tradisi umat Islam yang dimotivasi oleh ajaran agama dan telah dilakukan secara turun-menurun adalah berwakaf. Wakaf itu sendiri merupakan perbuatan hukum seseorang atau badan hukum atau kelompok orang yang menyisihkan sebagaian harta miliknya untuk diambil hasilnya atau dimanfaatkan bagi kesejahteraan masyarakat. Merujuk pada pengertian wakaf tersebut dapat dipahami bahwa bentuk benda yang dapat diwakafkan dapat berupa apa saja sepanjang benda tersebut dapat diambil manfaatnya bagi kepentingan menyejahterakan orang banyak. Akan tetapi bagi sebagian besar masyarakat Islam, khususnya umat Islam di Indonesia, konotasi wakaf masih terbatas pada wakaf benda tak bergerak seperti tanah dan bangunan yang diperuntukkan bagi tempat ibadah, pendidikan, rumah sakit dan sebagainya.

Pada era globalisasi dewasa ini, di mana peran uang mendominasi segala lini kehidupan manusia karena fungsinya yang praktis dan fleksibel, muncul permasalahan hukum Islam tentang keabsahan wakaf produktif dan wakaf dalam bentuk uang tunai. Setelah diketahui status hukum wakaf uang tunai tersebut, maka selanjutnya perlu pula digagas bagaimanakah strategi pengembangannya agar mobilisasi dan fungsionalisasi ajaran wakaf dapat benar-benar dirasakan oleh umat Islam.

B. Rumusan masalah

1. Bagaimana hukum wakaf uang

2. Bagaimana hukum wakaf produktif 


\section{BAB II}

\section{PEMBAHASAN}

\section{A. Pengertian wakaf}

Menurut al-Imam Abu Hanifah wakaf adalah menahan suatu benda milik seorang yang berwakaf dan menyedekahkan manfaatnya untuk tujuan kebaikan. Dengan pemahaman wakaf yang demikian maka kepemilikan terhadap benda tersebut tidak tercerabut dari tangan orang yang berwakaf dan ia boleh menarik kembali wakafnya atau menjualnya.

Sedangkan menurut jumhur ulama wakaf adalah menahan benda yang mungkin diberdayagunakan dengan tetap memelihara keutuhan bendanya dan memutus hak membelanjakan benda tersebut dari orag yang berwakaf, digunakan untuk keperluan yang diperbolehkan oleh syarak, atau dengan menggunakan keuntungannya bagi kebaikan, semata-mata guna mendekatkan diri kepada Allah swt. ${ }^{1}$

\section{B. Wakaf produktif}

Wakaf produktif adalah sebuah skema pengelolaan donasi wakaf dari umat, yaitu dengan memproduktifkan donasi tersebut, hingga mampu menghasilkan surplus yang berkelanjutan. Donasi wakaf dapat berupa benda bergerak, seperti uang dan logam mulia, maupun benda tidak bergerak, seperti tanah dan bangunan. Surplus wakaf produktif inilah yang menjadi sumber dana abadi bagi pembiayaan kebutuhan umat, seperti pembiayaan pendidikan dan pelayanan kesehatan yang berkualitas. ${ }^{2}$

Di antara hadis yang menjadi dasar dan dalil wakaf produktif adalah hadis yang menceritakan tentang kisah Umar bin al-Khaththab ketika memperoleh tanah di Khaibar. Setelah ia meminta petunjuk Nabi tentang tanah tersebut, Nabi menganjurkan untuk menahan asal tanah dan menyedekahkan hasilnya.

\footnotetext{
${ }^{1}$ Moh.Bahrudin, "Hukum Wakaf Uang dan Strategi Pengembangannya," Asas 7, no. 1 (2015): 1-10.

2 Wakaf al-azhar, "WAKAF PRODUKTIF," n.d., https://wakafalazhar.com/ptta-portfolio/wakafproduktif/.
} 
Hadis tentang hal ini adalah

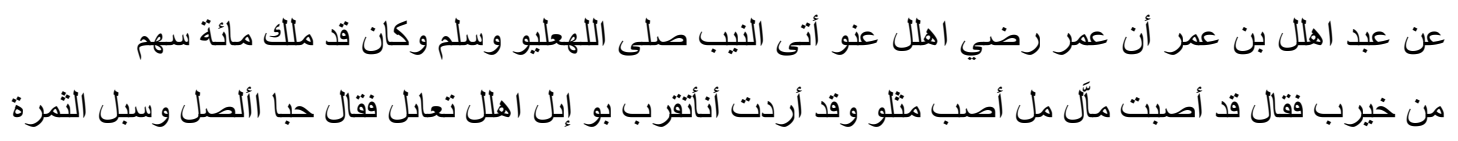

"Dari Abdullah bin Umar bahwa sesungguhnya Umar bin Khattab mendatangi Nabi SAW, (pada waktu itu) Umar baru saja memperoleh 100 kavling tanah Khaibar (yang terkenal subur), maka Umar berkata, „Saya telah memiliki harta yang tidak pernah saya miliki sebelumnya dan saya benar-benar ingin mendekatikan diri kepada Allah SWT melalui harta ini." Maka Rasulullah SAW bersabda, „Tahanlah asal harta tersebut dan alirkan manfaatnya". (H.R. al-Bukhari, Muslim, al-Tarmidzi, dan al Nasa'i).

Hadis lain yang menjelaskan wakaf adalah hadis yang diceritakan oleh Imam Muslim dari Abu Hurairah sebagai berikut:

$$
\text { اذا مات ألّنسان انقطع عمو آلّ من ثالث صدقة جارية أو علم بنتفع بو أو ولد صاحل يدعو لو }
$$

“Apabila seorang manusia itu meninggal dunia, maka terputuslah amal perbuatannya kecuali dari tiga sumber, yaitu sedekah jariah (wakaf), ilmu pengetahuan yang bisa diambil manfaatnya, dan anak soleh yang mendoakannya." (H.R. Muslim, al-Tirmidzi, al-Nasa' i, dan Abu Daud). ${ }^{3}$

para ulama sepakat (ijma ${ }^{e e}$ ) menerima wakaf sebagai satu amal jariah yang disyariatkan dalam Islam. Tidak ada orang yang dapat menafikan dan menolak amalan wakaf dalam Islam karena wakaf telah menjadi amalan yang senantiasa dijalankan dan diamalkan oleh para sahabat Nabi dan kaum Muslimin sejak masa awal Islam hingga sekarang.

Hadis tersebut menjadi dasar hukum wakaf produktif, dan dari hadis itu dapat disimpulkan bahwa wakaf produktif adalah harta benda wakaf yang

\footnotetext{
${ }^{3}$ Azis Suryani., "Wakaf Produktif dalam Kajian Hukum Islam dan Hukum Positif di Indonesia.," 2016, 32-67, http://idr.uin-antasari.ac.id/6076/5/BAB III.pdf.
} 
dikelola atau pengelolaannya untuk suatu kegiatan yang menghasilkan keuntungan untuk disalurkan pada program-program peningkatan kesejahteraan umat. Jadi, apapun kegiatan perwakafan baik pendidikan, kesehatan, ekonomi/bisnis, dan sebagainya selama dalam pengelolaannya memberikan hasil atau keuntungan maka hasil atau keuntungan itu harus dipergunakan untuk mewujudkan kesejahteraan umat. $^{4}$

Undang-undang Nomor 41 Tahun 2004 Tentang Wakaf ini menjadi momentum pemberdayaan wakaf secara produktif sebab di dalamnya terkandung pemahaman yang komprehensif dan pola manajemen pemberdayaan potensi wakaf secara modern. Dalam undang-undang wakaf yang baru ini konsep wakaf mengandug dimensi yang sangat luas. Ia mencakup harta tidak bergerak, maupun yang bergerak, termasuk wakaf uang yang penggunaannya sangat luas, tidak terbatas untuk pendirian tempat ibadah dan sosial keagamaan. Formulasi hukum yang demikian, jelas suatu perubahan yang sangat revolusioner. Jika dapat direalisasikan, akan memunculkan pengaruh yang berlipat ganda terutama dalam kaitannya dengan pemberdayaan ekonomi umat. Dengan demikian, Undang-undang Nomor 41 tahun 2004 diproyeksikan sebagai sarana rekayasa sosial (social engineering), melakukan perubahan-perubahan pemikiran, sikap dan perilaku umat Islam agar senafas dengan semangat undangundang tersebut. ${ }^{5}$

\section{Wakaf Uang}

Wakaf uang belum dikenal di zaman Rasulullah. Wakaf uang (cash waqf) baru dipraktekkan sejak awal abad kedua hijriyah. Imam az Zuhri (wafat $124 \mathrm{H}$ ) salah seorang ulama terkemuka dan peletak dasar tadwin al-hadits memfatwakan, dianjurkan wakaf dinar dan dirham untuk pembangunan sarana dakwah, sosial, dan pendidikan umat Islam.

\footnotetext{
${ }^{4}$ Lc Dr. Fahruroji dan MA, "WAKAF PRODUKTIF," iwakaf, n.d., http://iwakaf.or.id/detail/post/81/wakaf-produktif.html.

${ }^{5}$ Husni Thoyyar, "PENGELOLAAN WAKAF UANG DI INDONESIA," institut agama islam darussalam, n.d., https://www.iaid.ac.id/post/read/359/pengelolaan-wakaf-uang-di-indonesia.html.
} 
Di Turki, pada abad ke $15 \mathrm{H}$ praktek wakaf uang telah menjadi istilah yang familiar di tengah masyarakat. Wakaf uang biasanya merujuk pada cash deposits di lembaga-lembaga keuangan seperti bank, dimana wakaf uang tersebut biasanya diinvestasikan pada profitable business activities. Keuntungan dari hasil investasi tersebut digunakan kepada segala sesuatu yang bermanfaat secara sosial keagamaan. ${ }^{6}$

Menurt fatwa MUI tentang wakaf tunai yang ditetakan di Jakarta pada tanggal 11 Mei 2002, hukum wakaf tunai adalah jawaz atau boleh. Pada Undang-Undang Nomor 41 Tahun 2004 tentang wakaf, yaitu:

1. Wakaf Uang (Cash Wakaf/Wagf al-Nuqud) adalah wakaf yang dilakukan seseorang, kelompok orang, lembaga atau badan hukum dalam bentuk uang tunai.

2. Termasuk ke dalam pengertian uang adalah surat-surat berharga.

3. Wakafuang hukumnya jawaz (boleh)

4. Wakaf uang hanya boleh disalurkan dan digunakan untuk hal-hal yang dibolehkan secara syar'i.

5. Nilai pokok Wakaf Uang harus dijamin kelestariannya, tidak boleh dijual, dihibahkan, dan atau diwariskan. ${ }^{7}$

Ada beberapa pendapat ulama yang memperkuat tentang fatwa tentang wakaf tunai, yaitu:

1. Pendapat Imam Al-Zuhri

Imam Al-Zuhri memiliki pendapat bahwa wakaf tunai atau wakaf dengan

dinar hukumnya boleh. Caranya adalah dengan menjadikan dinar atau mata uang tertentu sebagai modal usaha dan hasil keuntungannya akan disalurkan melalui mauquf 'alaih (penerima manfaat wakaf).

${ }^{6}$ BADAN WAKAF INDONESIA, “WAKAF UANG," n.d.

7 BADAN WAKAF INDONESIA. 
Dari Imam Al-Zuhri bahwasanya ia berkata, "Tentang seseorang yang mewakafkan seribu dinar di jalan Allah, dan uang tersebut diberikan kepada pembantunya untuk diinvestasikan, kemudian keuntungannya diserahkan kepada orang-orang miskin dan kerabat". (Shahih Bukhari, 4/14)

2. Pendapat Sebagian dari Ulama Mahdzab Hanafi

Para ulama dari mahdzab Hanafi memperbolehkan wakaf uang dinar dan dirham sebagai pengecualian, atas dasar Istihsan bi al-'urfi. Berdasarkan atsar Abdullah bin Mas'ud R.A: “Apa yang dipandang baik oleh kaum Muslimin maka dalam pandangan Allah adalah baik, dan apa yang dipandang buruk oleh kaum Muslimin maka dalam pandangan Allah pun buruk".

3. Pendapat Sebagian Ulama Mahdzab Syafii

Sebagian ulama dari mahdzab Syafii memperbolehkan adanya wakaf uang. Hal ini seperti yang disampaikan Al-Mawardi, Al-Hawi Al-Kabir, Dr. Mahmud Mathraji dari Darul Fikri, Juz IX, “Abu Tsyar meriwayatkan dari Imam al-Syafi’i tentang kebolehan wakaf dinar dan dirham (uang)". 8

Berikut akan dikemukakan dasar hukum atau dalil kebolehan wakaf uang tunai, di dalam Al-Qur'an :

a. Allah swt. telah mensyariatkan wakaf, menganjurkan dan menjadikan sebagai salah satu bentuk kebajikan dan sebagai perantara untuk mendekatkan diri kepada Allah swt. Dalam Q.S. al-Hajj :77 Allah swt. berfirman :

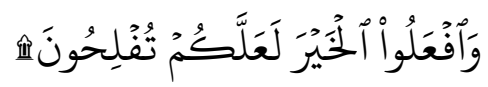

Artinya : Perbuatlah kebajikan, supaya kamu mendapatkan kemenangan. (Al-Hajj ; 77)

${ }^{8}$ Fahmi Abidin, "Belajar soal Wakaf Tunai, Ini Menurut Ulama dan Manfaatnya," IDXCHANNEL, n.d., https://www.idxchannel.com/syariah/belajar-soal-wakaf-tunai-ini-menurut-ulama-dan-manfaatnya. 
b. Melalui Q.S. Ali Imran : 92 Allah swt. memerintahkan untuk menginfakkan sebagian harta kita guna memperoleh kebajikan, meski harta tersebut adalah kesayangan kita.

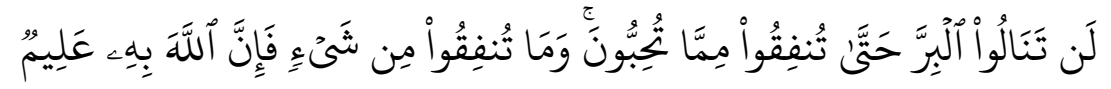

Artinya: -Kamu sekali-kali tidak sampai kepada kebajikan (yang sempurna), sebelum kamu menafkahkan sebagaian harta yang kamu cintai. Dan apa saja yang kamu nafkahkan, maka sesungguhnya Allah mengetahuinya. (Al-Imran : 92)

c. Dalam Q.S. al-Baqarah : 261 Allah swt. menjanjikan pahala yang berlipat ganda bagi hambanya yang mau menyedekahkan hartanya di jalan Allah.

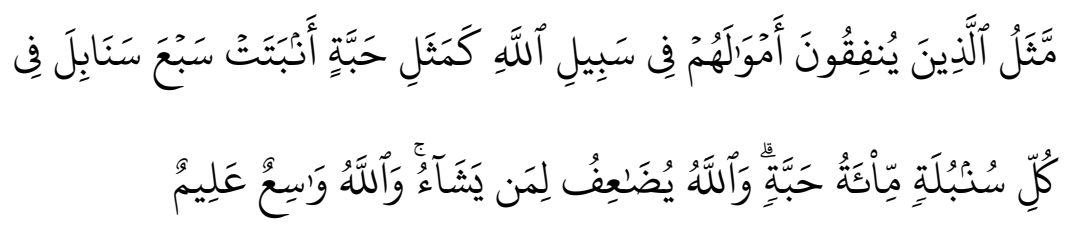

Artinya : Perumpamaan (nafkah yang dikeluarkan oleh) orang yang menafkahkan hartanya di jalan Allah adalah serupa dengan benih yang menumbuhkan tujuh bulir, pada setiap bulir terdapat seratus biji, Allah melipatgandakan (pahala) bagi siapa yang Dia kehendaki dan Allah Maha Luas (Karunia-Nya) lagi Maha Mengetahui. (Al-Baqarah : 261). ${ }^{9}$

Nilai lebih wakaf uang tunai adalah daya jangkaunya yang dapat menyasar ke seluruh strata masyarakat karena wakaf tunai dapat dilakukan oleh siapa saja, dalam artian waqif tidak memerlukan nominal uang yang besar untuk dibelikan benda tidak bergerak.

Dengan demikian wakaf dapat diberikan dalam bentuk satuan - satuan nominal mata uang yang kecil. Sebagai contoh, sebuah sertifikat wakaf uang tunai yang dikelurkan oleh sebuah lembaga wakaf dapat dibayar menurut harga per-

\footnotetext{
${ }^{9}$ Moh.Bahrudin, "Hukum Wakaf Uang dan Strategi Pengembangannya."
} 
lembar atau satuan Rp. 5.000,- sehingga memungkinkan partisipasi atau memperluas jumlah waqif. ${ }^{10}$

${ }^{10}$ Moh.Bahrudin. 


\title{
BAB III
}

\section{PENUTUP}

\begin{abstract}
A. Kesimpulan
Pengaturan wakaf produktif dan wakaf uang telah dimulai pada saat lahirnya Undang-undang No. 41 Tahun 2004 Tentang Wakaf dengan PP No. 42 Tahun 2006. Dan hukum dalil dalam Al-Quran serta Ada beberapa pendapat ulama yang memperkuat tentang fatwa tentang wakaf tunai. Pada era globalisasi dewasa ini, di mana peran uang mendominasi segala lini kehidupan manusia karena fungsinya yang praktis dan fleksibel, muncul permasalahan hukum Islam tentang keabsahan wakaf produktif dan wakaf dalam bentuk uang tunai. Setelah diketahui status hukum wakaf uang tunai tersebut.

B. Saran

Dengan adanya status hukum tentang wakaf produktif dan wakaf uang, baik dari sudut pandang hukum Islam maupun hukum positif, jadi kiranya masyarakat tidak ragu-dalam melaksanakan wakaf produktif di kemudian hari. Lembaga-lemabaga wakaf di Indonesia, mampu mengoptimalkan wakaf produktif dan wakaf uang sebaik mungkin, agar dapat melaksanakan tujuan wakaf itu sendiri, yaitu berguna membantu untuk membantu perekonomian umat di Indonesia
\end{abstract}




\section{DAFTAR PUSTAKA}

Azis Suryani. "Wakaf Produktif dalam Kajian Hukum Islam dan Hukum Positif di Indonesia.," 2016, 32-67. http://idr.uin-antasari.ac.id/6076/5/BAB III.pdf.

BADAN WAKAF INDONESIA. "WAKAF UANG," n.d.

Dr. Fahruroji, Lc, dan MA. "WAKAF PRODUKTIF." iwakaf, n.d. http://iwakaf.or.id/detail/post/81/wakaf-produktif.html.

Fahmi Abidin. "Belajar soal Wakaf Tunai, Ini Menurut Ulama dan Manfaatnya." IDXCHANNEL, n.d. https://www.idxchannel.com/syariah/belajar-soal-wakaftunai-ini-menurut-ulama-dan-manfaatnya.

Husni Thoyyar. "PENGELOLAAN WAKAF UANG DI INDONESIA.” institut agama islam darussalam, n.d. https://www.iaid.ac.id/post/read/359/pengelolaanwakaf-uang-di-indonesia.html.

Moh.Bahrudin. "Hukum Wakaf Uang dan Strategi Pengembangannya." Asas 7, no. 1 (2015): 1-10.

Wakaf al-azhar. "WAKAF PRODUKTIF," n.d. https://wakafalazhar.com/pttaportfolio/wakaf-produktif/. 